Sains Malaysiana 49(9)(2020): 2169-2185

http://dx.doi.org/10.17576/jsm-2020-4909-15

\title{
Non-Isothermal Crystallization Kinetics of Poly(Lactic Acid)/Kenaf Fiber Composites
}

\author{
(Kinetik Penghabluran bukan Isoterma Komposit Poli(Laktik Asid)/Serat Kenaf)
}

\author{
ADIBAH BORHAN \& RAZAINA MAT TAIB*
}

\section{ABSTRACT}

The non-isothermal crystallization behavior of poly(lactic acid) (PLA)/kenaf fiber (KF) composites was investigated using differential scanning calorimetry (DSC) at different cooling rates (1, 2.5, 5, and $7.5{ }^{\circ} \mathrm{C} / \mathrm{min}$ ) with various $\mathrm{KF}$ sizes from 25 to $300 \mu \mathrm{m}$. The modified Avrami, Ozawa, and Mo methods were applied to study the non-isothermal crystallization kinetics of neat PLA and PLA/KF composites. It was found that KF size of 80-106 $\mu$ m acts as nucleating agent during non-isothermal crystallization of PLA/KF composites since the values of half-time of crystallization ( $\left.t_{1 / 2}\right)$ of PLA80 were the fastest as compared to neat PLA and other PLA/KF composites at a given cooling rate. The AvramiJeziorny crystallization rate constant $(Z)$ increased upon increased of cooling rates for both neat PLA and PLA/KF composites indicating the improvement in crystallization. However, only the $Z_{c}$ values for PLA80 were faster than PLA/ $K F$ composites but slower than neat PLA at a certain cooling rate. The Ozawa method did not apply satisfactorily for both neat PLA and PLA/KF composites. Meanwhile, the results showed that the Mo method can be successfully applied by providing a good fitting for all cooling rates of neat PLA and PLA/KF composites. The Kissinger activation energy ( $\triangle E)$ of PLA80 recorded the lowest value indicating the size of $K F$ between 80-106 $\mu \mathrm{m}$ accelerated the noncrystallization of PLA.

Keywords: Differential scanning calorimetry; kenaf fiber; non-isothermal crystallization; poly(lactic acid)

\section{ABSTRAK}

Tingkah laku penghabluran bukan isoterma komposit poli(laktik asid) (PLA)/serat kenaf (KF) dikaji dengan menggunakan kalorimetri pengimbasan perbezaan (DSC) pada kadar pendinginan yang berbeza (1, 2.5, 5 dan 7.5

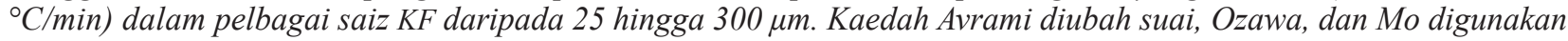
untuk mengkaji kinetik penghabluran bukan isoterma PLA tulen dan komposit PLA/KF. Telah didapati bahawa saiz KF 80-106 $\mu \mathrm{m}$ bertindak sebagai agen nukleasi semasa penghabluran bukan isoterma komposit PLA/KF kerana nilai-nilai separuh masa penghabluran ( $\left.t_{1 / 2}\right)$ PLA80 adalah terpantas berbanding dengan PLA tulen dan PLA/KF komposit mengikut kadar pendinginan yang diberikan. Kadar tetap penghabluran Avrami-Jeziorny $(Z)$ meningkat apabila peningkatan kadar pendinginan untuk kedua-dua PLA tulen dan komposit PLA/KF menunjukkan peningkatan dalam penghabluran. Walau bagaimanapun, nilai $Z_{c}$ untuk PLA80 lebih cepat daripada komposit PLA/KF tetapi lebih perlahan daripada PLA tulen pada kadar pendinginan tertentu. Kaedah Ozawa tidak menunjukkan penerapan yang baik untuk PLA tulen dan komposit PLA/KF. Sementara itu, keputusan menunjukkan bahawa kaedah Mo dapat diterapkan dengan berkesan dengan menunjukkan garisan yang kemas bagi semua kadar pendingin PLA tulen dan komposit PLA/KF. Pengaktifan Kissinger (UE) PLA80 mencatatkan nilai terendah yang menunjukkan saiz KF antara 80$106 \mu \mathrm{m}$ mempercepatkan penghabluran semula PLA.

Kata kunci: Kalorimetri pengimbasan perbezaan; penghabluran bukan isoterma; poli(laktik asid); serat kenaf

\section{INTRODUCTION}

Many industries attempt to reduce their dependency on petroleum-based products for economic and environmentally sustainable development. A major attention has been shifted to biopolymers as alternatives to synthetic a non-degradable polymer (Elsawy et al. 2017). The petroleum-based products are discarded into the environment and subject to non-degraded after used.
As a result, a massive amount of discarded packaging is excluded from natural recycling (Avérous 2008). To overcome these environmental problems, there is an urgent need for the development of biodegradable materials that can be degraded over a relatively short time, help reduce emissions of toxic and greenhouse gases, and control the ever-increasing depletion rate of fossil fuel resources (Elsawy et al. 2017). Biodegradable polymers produced 
from renewable resources are attracting much attention in view of the growing concerns for the environment. A widely used biodegradable polymers are poly(butylene succinate) (PBS), poly(hydroxy alkanoate) (PHA), poly(butylene adipate-co-terephthalate) (PBAT), and poly(lactic acid) (PLA). One of the promising and attractive biodegradable thermoplastic polymers being developed is PLA (Chung et al. 2018).

PLA is a commercially available bio-based linear aliphatic polyester which can be yielded by direct polymerization of a basic building block lactic acid (Ho et al. 2015; Jonoobi et al. 2010), that is produced by bacterial fermentation of carbohydrates in corn, sugar cane or cheese whey (Ho et al. 2015). The monomer, lactic acid (LA) usually presents with two enantiomeric forms known as L-LA and D-LA. The presence of these two enantiomers will result in a wide range of properties from completely amorphous to semicrystalline PLA, depending on the ratio and distribution of enantiomeric units along polymer chains (Saeidlou et al. 2012; Volpe et al. 2018). Normally, commercial PLA resin contains of random L-isomer rich copolymers with a low amount of D-isomer co-units. The D-LA percentage can influence the maximum crystallinity of the material. Upon increases in D-LA percentage, the crystallization kinetics becomes slower and the maximum attainable crystalline content reduces. Small amounts of the D-LA form are usually used, to change mechanical properties and melting temperature that also increases with the decreasing of D-LA percentage (Volpe et al. 2018).

PLA has superior mechanical, optical properties, and good processability (Jain et al. 2012; Notta-Cuvier et al. 2014; Silverajah et al. 2012), when using conventional melt-processing techniques such as extrusion, injection molding, and melt-spinning (Notta-Cuvier et al. 2014). In addition, PLA has attractive physical properties in terms of tensile strength and stiffness, biodegradability and excellent biocompatibility, and superior transparency (Jain et al. 2012; Notta-Cuvier et al. 2014; Silverajah et al. 2012). These advantages are in parallel with recent technological developments in PLA production, where it has rapidly expanded its applications as a competitive commodity polymer in a variety of processes ( $\mathrm{Li}$ et al. 2017; Notta-Cuvier et al. 2014). In the industry, PLA can be processed in a way similar to poly(propylene) (PP) (Suryanegara et al. 2009). Compared to PP, PLA not only exhibits higher modulus, but also higher storage modulus and flexural properties. The mechanical and thermal properties of the PLA are also comparable to PP (Yusoff et al. 2016). However, despite of these qualities, PLA has some significant limitations such as poor gas barrier performance and water-permeability, relatively low thermal resistance, low tensile elongations (less than 4\%), low toughness (characterized by Izod impact strength as low as $2.5-3 \mathrm{~kJ} / \mathrm{m}^{2}$ ) (Notta-Cuvier et al. 2014; Silverajah et al. 2012), high brittleness, and slow crystallization rate (Silverajah et al. 2012; Zaldua et al. 2016). Thus, it is necessary to enhance these properties if PLA is to be used in long-term application on a large scale.

Since PLA is a thermoplastic, it usually undergoes pre-heating before the forming process. PLA re-crystallizes during heating due to its semi-crystalline nature, and results in different physical properties. Hence, crystallization and crystallization kinetics play important roles in the manufacturing process and product performance (Chen et al. 2017). Some studies reported that PLA blending with other polymers, fillers or nucleation agents can improve crystallinity (Lin et al. 2013; Ren et al. 2006). Yet, these additives may result in poor physical performance due to poor compatibility between the heterogeneous phases or prevent the PLA composite from biodegrading (Chen et al. 2017). In an effort to develop new plastic materials with low environmental impact, PLA polymers were compounded with natural fibers to reduce costs of production while maintaining their properties (Kowalczyk et al. 2011). Natural fibers are also lightweight, locally available in abundance, and obtained from renewable resources (Akhtar et al. 2016; Zamri et al. 2015). The most common natural fibers such as are hemp (Masirek et al. 2007), ramie (Yu et al. 2015), bamboo (Lee \& Wang 2006) and kenaf (Akhtar et al. 2016; Zamri et al. 2015) were utilized to be used as a replacement for conventional reinforcing agents such as glass fibers, carbon fibers, and talc (Petinakis et al. 2009). Among different types of natural fibers, kenaf fiber (KF) has recently been gaining a lot of attention because it is cheap and grown under various climates (Akhtar et al. 2016). KF has been mainly used for textiles and paper before, and recently composites of KF and plastics have been studied owing to its promising properties (Pan et al. 2007).

Properties of fiber-reinforced composites are strongly influenced by interactions between the components. A research from El-Shekeil et al. (2011) stated that different size of short kenaf fibers as the reinforcement in the composite of thermoplastic polyurethane (TPU) demonstrated significant influence on the tensile, flexural and impact strength. The study found out that amongst the fiber size range from $<125$ to $425 \mu \mathrm{m}$, only fiber size between 125 and $300 \mu \mathrm{m}$ presented the best tensile and flexural strength and modulus and considered to be optimum size in improving mechanical properties. A larger fiber size showed only a slight increment of impact strength of about 7\% (El-Shekeil et al. 2011). Furthermore, natural fiber was also reported to play a role as a nucleating agent in the PLA crystallization process. Previous studies showed that the addition of KF accelerates the crystallization rate, improves the thermal stability, and enhances the tensile modulus and storage modulus of the 
PLA composites (Pan et al. 2007). However, almost barely available researches are focusing on effects of natural fiber sizes on PLA in the non-isothermal crystallization kinetics study. Thus, the objective of this work was to fabricate the natural composites from KF and PLA by the melt-mixing method, and to investigate the effect of KF size on the non-isothermal crystallization behavior of PLA. The non-isothermal crystallization kinetics was performed using Avrami, Ozawa, and Mo models. The activation energy for crystallization were estimated by the Kissinger method.

\section{MATERIALS AND METHODS}

\section{MATERIALS}

Polylactic acid (PLA 4032D) was purchased from NatureWorks ${ }^{\circledR}$ LLC (Minnetonka, Minnesota). The physical properties are given such as specific gravity = 1.24; weight average molecular weight $\mathrm{M}_{\mathrm{w}}=140,000 \mathrm{~g} /$ $\mathrm{mol}, \mathrm{M}_{\mathrm{w}} / \mathrm{M}_{\mathrm{n}}$; melt index, MFI $=7 \mathrm{~g} / 10 \mathrm{~min}\left(210^{\circ} \mathrm{C}, 2.16\right.$ $\mathrm{kg}$ ); and crystalline melting temperature, $T_{\mathrm{m}}=155-170$ ${ }^{\circ} \mathrm{C}$. PLA 4032D is delivered as semi-crystalline grade pellet with ratio $98 \%$ L-lactide to $2 \%$ D-lactide units. PLA was dried in vacuum oven at $60{ }^{\circ} \mathrm{C}$ for $24 \mathrm{~h}$ prior to processing and testing operation. KF particles were sieved with Retsch Test Sieve Model 5667 to five ranges of micron sizes of $300-355,212-250,106-212,80-$ 106 , and $25-40 \mu \mathrm{m}$.

\section{PREPARATION OF COMPOSITES}

PLA and KF were dried in an oven at $60{ }^{\circ} \mathrm{C}$ for $24 \mathrm{~h}$ prior to blending. PLA and KF were blended by melt-mixing with an internal mixer (Haake Rheomix Polydrive R $600 / 610$ equipped with two rotating blades). Melt-mixing was performed at $170{ }^{\circ} \mathrm{C}$ to ensure PLA and PLA/KF composites were completely melted. The rotor speed was $50 \mathrm{rpm}$ to make sure the blends were homogenous. PLA was feed into internal mixer and allowed to melt for $2 \mathrm{~min}$ before adding KF. Then, both materials were allowed to mix for 5 min before collecting the composites from the internal mixer. The pellets were collected and dried before compression molding processing. Samples were pressed into sheet form of $1 \mathrm{~mm}$ thickness by using a Kao Tieh Go Tech compression molding machine. The processing temperature and applied pressure were $170{ }^{\circ} \mathrm{C}$ and $14 \mathrm{MPa}$, respectively. The mold was pre-heated for 5 min without pressure to prevent formation of bubbles, pressed for $3 \mathrm{~min}$ with pressure applied, and cooled for $3 \mathrm{~min}$ in cool press equipped with tap water cooling. The composition of PLA to KF particles are fixed at 95 and $5 \mathrm{wt}$. \%, respectively. The list of samples of neat PLA and PLA/KF composites are displayed in Table 1.

TABLE 1. List of samples of neat PLA and PLA/KF composites

\begin{tabular}{|c|c|}
\hline Sample & KF sizes $(\mu \mathrm{m})$ \\
\hline PLA & - \\
\hline PLA25 & $25-40$ \\
\hline PLA80 & $80-106$ \\
\hline PLA106 & $106-212$ \\
\hline PLA212 & $212-250$ \\
\hline PLA300 & $300-355$ \\
\hline
\end{tabular}

\section{DIFFERENTIAL SCANNING CALORIMETRY (DSC)}

The non-isothermal crystallization kinetics properties of PLA and PLA/KF composites were studied by using Mettler Toledo differential scanning calorimetry (DSC) under nitrogen flow. Samples weighed about 8-10 mg were placed and sealed in an aluminium pan. At first heating, the sample were heated from 30 to $200{ }^{\circ} \mathrm{C}$ at heating rate $30{ }^{\circ} \mathrm{C} / \mathrm{min}$ and kept at $200{ }^{\circ} \mathrm{C}$ for $5 \mathrm{~min}$ to remove thermal history. The samples were then cooled to $30{ }^{\circ} \mathrm{C}$ at cooling rates of $1{ }^{\circ} \mathrm{C} / \mathrm{min}$ and heated again to $200{ }^{\circ} \mathrm{C}$ at heating rate of $10^{\circ} \mathrm{C} / \mathrm{min}$ (second heating). This cycles was repeated with different cooling rates $(2.5,5$, and 7.5 ${ }^{\circ} \mathrm{C} / \mathrm{min}$ ). The endothermal flow curves as a function of temperature were recorded to analyse the non-isothermal crystallization process. The second heating is carried out to determine melting temperature $\left(T_{\mathrm{m}}\right)$, glass transition temperature $\left(T_{\mathrm{g}}\right)$, cold crystallization temperature $\left(T_{\mathrm{cc}}\right)$, enthalphy of cold crystallization $\left(\Delta H_{\mathrm{cc}}\right)$ and enthalphy of fusion $\left(\Delta H_{\mathrm{m}}\right)$ of the crystallized samples. $X_{\mathrm{c}}$, the degree of crystallinity was also determined by using the equation (Bouzouita et al. 2016): 


$$
X_{c}=\frac{\Delta H_{m}-\Delta H_{c c}}{\Delta H_{m}^{\circ} \times \emptyset_{P L A}} \times 100 \%
$$

where $\left(\varnothing_{\text {PLA }}\right)$ is the weight fraction of polymer; and $\Delta H^{\circ}{ }_{m}$ is the theoretical enthalpy value for $100 \%$ crystalline PLA, which can be found in the literature to be $93 \mathrm{~J} / \mathrm{g}$ (Gorrasi \& Pantani 2013).

\section{RESULTS AND DISCUSSION}

\section{NON-ISOTHERMAL CRYSTALLIZATION BEHAVIOR AND SUBSEQUENT MELTING BEHAVIORS}

The non-isothermal crystallization endotherms of neat PLA and PLA/KF composites filled with different KF sizes are shown in Figure 1. All samples were melted and cooled at different cooling rates ranging from 1 to $7.5^{\circ} \mathrm{C} / \mathrm{min}$. The cooling parameters are recorded in Table 2. $T_{\mathrm{p}}$ is the peak temperature where the crystallization rate was at the maximum and $\Delta H_{\mathrm{c}}$ is the crystallization enthalpy. It is evident from these curves that upon increase in cooling rate, the crystallization endotherms of neat PLA and PLA/ KF composites becomes broader and shift towards lower temperature range. At a lower cooling rate $\left(\phi \leq 2.5^{\circ} \mathrm{C} /\right.$ $\mathrm{min}$ ), there is sufficient time to activate nuclei and polymer chain move faster than the change of temperature; and thus, it takes a longer time to complete crystallization which leads to a higher temperature (Bai \& Dou 2016). However, when the samples are cooled at higher cooling rate $\left(\phi \geq 5{ }^{\circ} \mathrm{C} / \mathrm{min}\right)$, the molecular motion of the PLA slows down since there is less available time for PLA chains to crystallize. Hence, a higher supercooling $\left(\Delta T_{\mathrm{s}}=\right.$ $T_{\mathrm{m}}-T_{\mathrm{p}}, T_{\mathrm{m}}$ is the melting temperature) is required to initiate crystallization, indicating a lower $T_{\text {p }}$ (Bin et al. 2011; Myoung et al. 2016; Rinawa et al. 2015; Xiao et al. 2010).

The $T_{\mathrm{p}}$ and $\Delta H_{\mathrm{c}}$ are widely believed related to the crystallization rate and represent the difficulty level of crystallization process (Bai \& Dou 2016). Normally, if the polymer has faster crystallization rate, it will crystallize at higher temperature (Bai \& Dou 2016). The values of $T_{\mathrm{p}}$ of the PLA/KF composites shift to lower temperature as compared to the neat PLA at specified cooling rate. It indicates that the addition of KF slightly decreased the rate of crystallization and the melt-crystallization temperature of the PLA. The values of $T_{\mathrm{p}}$ of the PLA80 composite shift slightly lower $\left(0.4-1.7^{\circ} \mathrm{C}\right)$ than neat PLA. However, $T_{p}$ of PLA80 are slightly higher than PLA/KF composites at lower cooling rates $\left(\phi \leq 2.5^{\circ} \mathrm{C} / \mathrm{min}\right)$; which imply that $\mathrm{KF}$ with size of 80-106 $\mu \mathrm{m}$ have a better melt-crystallization temperature and faster crystallization rate than other sizes of $\mathrm{KF}$ in the PLA/KF composites. But, at higher cooling rates $\left(\phi \geq 5{ }^{\circ} \mathrm{C} / \mathrm{min}\right)$, the $T_{\mathrm{p}}$ values of PLA80 are almost comparable to other PLA/KF composites probably because PLA cannot crystallize completely and affecting the $T_{\mathrm{p}}$ values (Pan et al. 2008). These minor temperature difference, however, could not show the difference of crystallization rate convincingly. Hence, the $\Delta H_{\mathrm{c}}$ value is required to denote the difficulty level of crystallization of the samples. The higher $\Delta H_{\mathrm{c}}$ value, the more perfect the crystallization is produced (Bai \& Dou 2016). In general, $\Delta H_{\mathrm{c}}$ value of neat PLA is higher than most PLA/ $\mathrm{KF}$ composites indicating the crystallization is easier and perfect crystallization is created in neat PLA. Likewise, upon increased in sizes of $\mathrm{KF}$, the $\Delta H_{\mathrm{c}}$ value of the PLA/ $\mathrm{KF}$ composites is slightly decreased. It can be suggested that when the size of KF is increased, the crystallization becomes difficult and imperfect crystals are produced. The $T_{\mathrm{p}}$ and $\Delta H_{\mathrm{c}}$ values slightly decreased upon addition of KF into the PLA matrix, and did not displayed obvious dependence on the fiber sizes; are most probably occurred due to the physical hindrance of fibers to the motion (Bin et al. 2011) of PLA chains which retards the crystallization of PLA.

TABLE 2. Non-isothermal crystallization of PLA and PLA/KF composites at different cooling rates

\begin{tabular}{|c|c|c|c|c|c|c|c|c|}
\hline $\begin{array}{c}\text { Cooling } \\
\text { rate, } \varnothing \\
\left({ }^{\circ} \mathrm{C} / \mathrm{min}\right) \\
\end{array}$ & Sample & $\begin{array}{c}T_{\mathrm{p}} \\
\left({ }^{\circ} \mathrm{C}\right)\end{array}$ & $\begin{array}{l}\Delta H_{\mathrm{c}} \\
(\mathrm{J} / \mathrm{g})\end{array}$ & $\begin{array}{c}t_{1 / 2} \\
(\min )\end{array}$ & Sample & $\begin{array}{c}T_{\mathrm{p}} \\
\left({ }^{\circ} \mathrm{C}\right)\end{array}$ & $\begin{array}{l}\Delta H_{\mathrm{c}} \\
(\mathrm{J} / \mathrm{g})\end{array}$ & $\begin{array}{c}t_{1 / 2} \\
(\min )\end{array}$ \\
\hline 1 & \multirow{4}{*}{ PLA } & 122.2 & 42.02 & 9.67 & \multirow{4}{*}{ PLA106 } & 118.2 & 39.74 & 12.46 \\
\hline 2.5 & & 113.4 & 38.75 & 6.42 & & 107.8 & 35.98 & 7.36 \\
\hline 5 & & 95.4 & 35.39 & 5.11 & & 94.5 & 32.33 & 5.45 \\
\hline 7.5 & & 90.5 & 24.92 & 4.08 & & 90.6 & 21.82 & 3.99 \\
\hline 1 & \multirow{4}{*}{ PLA25 } & 119.1 & 39.50 & 11.01 & \multirow{4}{*}{ PLA212 } & 119.1 & 35.75 & 11.19 \\
\hline 2.5 & & 109.3 & 38.35 & 6.80 & & 110.4 & 38.69 & 7.05 \\
\hline 5 & & 93.9 & 33.08 & 5.28 & & 93.0 & 31.24 & 5.65 \\
\hline 7.5 & & 90.4 & 17.12 & 3.60 & & 89.3 & 16.63 & 3.80 \\
\hline 1 & \multirow{4}{*}{ PLA80 } & 121.8 & 40.81 & 8.94 & \multirow{4}{*}{ PLA300 } & 117.1 & 31.58 & 12.78 \\
\hline 2.5 & & 114.3 & 37.16 & 5.72 & & 108.9 & 34.49 & 7.95 \\
\hline 5 & & 93.67 & 32.61 & 4.41 & & 91.4 & 28.51 & 5.58 \\
\hline 7.5 & & 89.8 & 16.28 & 3.67 & & 88.5 & 11.90 & 3.92 \\
\hline
\end{tabular}


The curves showed that when cooling rate of neat PLA and PLA/KF composites reached $2.5^{\circ} \mathrm{C} / \mathrm{min}$, a small shoulder can be observed between 95 and $105{ }^{\circ} \mathrm{C}$ after crystallization peak dominant appeared; showing that the change of the crystallization mechanism maybe take place in this region (Pan et al. 2008). The $\Delta H_{\mathrm{c}}$ value of neat PLA and PLA/KF composites showed broad double crystallization peak temperature upon increased in cooling rates $\left(\phi \geq 2.5^{\circ} \mathrm{C} / \mathrm{min}\right)$. According to Jalali et al. (2017), PLA is a polymorphic material which exhibits two crystalline phase known $\alpha$ and $\alpha^{\prime}$, depending on temperature it is melted and cooled. The $\alpha$ phase forms at temperature above $120^{\circ} \mathrm{C}$ while $\alpha^{\prime}$ develops at temperature below $100^{\circ} \mathrm{C}$. A mixture of $\alpha$ and $\alpha^{\prime}$ coexists in the range of temperature between 100 and $120^{\circ} \mathrm{C}$. A double crystallization peak was clearly shown for self-nucleated PLA samples indicating the different crystallization efficiency of the two PLA phases using a specific thermal protocol (Jalali et al. 2017).
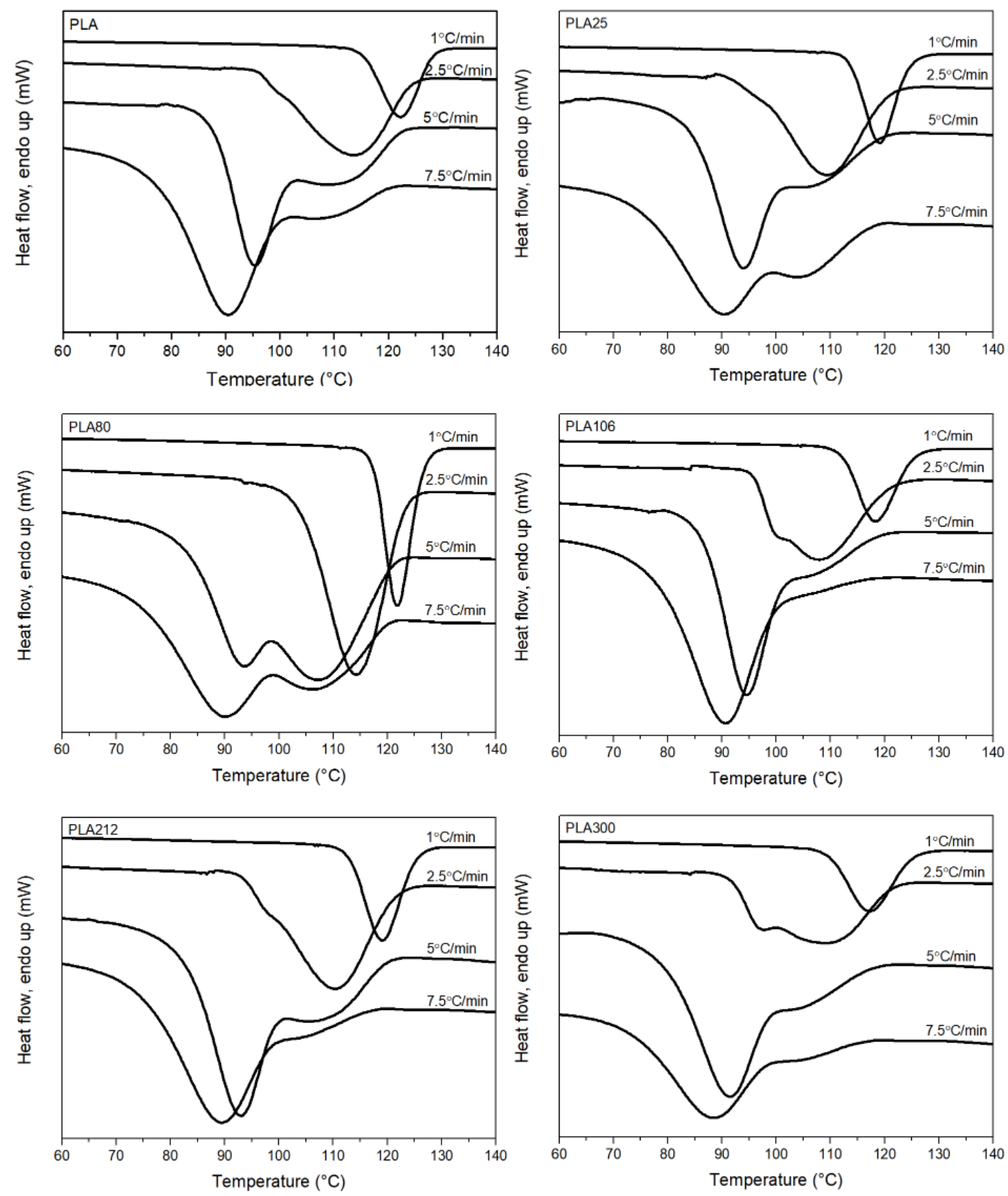

FIGURE 1. Non-isothermal crystallization endotherm of PLA and PLA/KF composites at different cooling rates 
The subsequent melting thermograms for neat PLA and the PLA/KF composites after non-isothermal crystallization process are shown in Figure 2. Thermal characteristics of neat PLA and PLA/KF composites are summarized in Table 3. It can be observed that at low cooling rate $\left(\phi \leq 5^{\circ} \mathrm{C} / \mathrm{min}\right)$, the $T_{\mathrm{g}}$ and $T_{\mathrm{cc}}$ unable to be observed and become apparent once the cooling rate reaching $7.5^{\circ} \mathrm{C} / \mathrm{min}$. Hence, it can be seen that the neat PLA exhibited $T_{\mathrm{g}}$ and $T_{\mathrm{cc}}$ at $51.5^{\circ} \mathrm{C}$ and $88.1{ }^{\circ} \mathrm{C}$, respectively, only when reaching cooling rate of $7.5^{\circ} \mathrm{C} /$ $\min$. The $T_{\mathrm{g}}$ of PLA/KF composites displayed insignificant changes upon increased in KF sizes. The subsequent heating scans for PLA/KF composites of various KF sizes after cooling from the melt exhibited similar trends as neat PLA. The $T_{\text {cc }}$ peak appeared more apparent upon increased in cooling rate probably because of the crystallization induction period was reduced due to the presence of crystalline nuclei which already formed during the cooling process (Xiao et al. 2010). Although these nuclei denoted a small crystalline group upon completion, they will increase the crystallization rate upon heating since the crystalline structure is already nucleated densely as compared to the polymer which is cooled from the melt.

PLA cooled at high cooling rate $\left(\phi \geq 7.5^{\circ} \mathrm{C} / \mathrm{min}\right)$ may be difficult to crystallize or crystallize partially (Xiao et al. 2010). However, un-crystallised or partially crystallized PLA can be formed easily during the second heating which resulting in higher $\Delta H_{\mathrm{cc}}$. On the contrary, PLA which is cooled at slow cooling rate may crystallize partially or completely. Thus, the degree of supercooling increased due to the decrease of cooling rates, and crystal formed during cooling become more perfect (Xiao et al. $2010)$. Contrary, at low cooling rate $\left(\phi \leq 5^{\circ} \mathrm{C} / \mathrm{min}\right)$, PLA has enough time to crystallize completely upon cooling which leads to disappearance of $T_{\text {cc }}$ upon second heating. The $T_{\text {cc }}$ value of PLA/KF composites of various sizes of KF increased as compared to neat PLA. The $X_{\mathrm{c}}$ value of neat PLA upon increased as cooling rate decreased. The PLA/ $\mathrm{KF}$ composites of various sizes of $\mathrm{KF}$ also recorded the decreased of $X_{\mathrm{c}}$ value upon increased in cooling rate. This
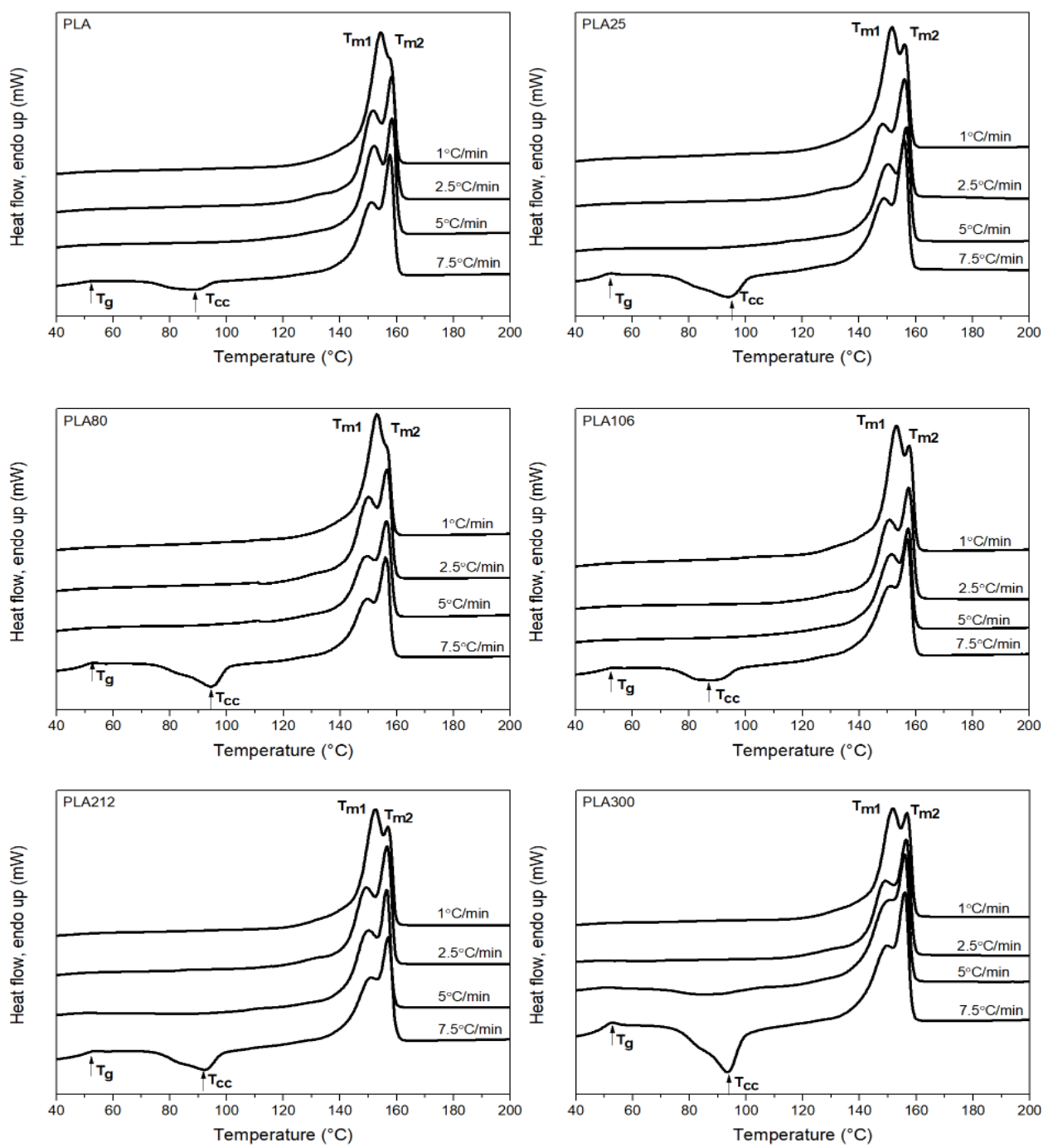

FIGURE 2. Subsequent melting endotherms of PLA and PLA/KF composites at a heating rate of $10^{\circ} \mathrm{C} / \mathrm{min}$ after non-isothermal crystallization 
condition is expected since the increased in cooling rate decreased the ability of the PLA to crystallize. Meanwhile, $X_{c}$ values of PLA/KF composites also appeared lower than neat PLA. These results occurred probably due to the presence of KF hinder the migration and diffusion of PLA molecular chains to the surface of the nucleus in the composites (Pan et al. 2007).

The neat PLA exhibited a single melting peak at 154.3 ${ }^{\circ} \mathrm{C}$ with a possible shoulder at $158.1{ }^{\circ} \mathrm{C}$ at $1{ }^{\circ} \mathrm{C} / \mathrm{min}$. In addition, two distinct melting peaks were observed for all of the higher cooling rates in neat PLA, and all of the $\mathrm{PLA} / \mathrm{KF}$ composites regardless of the cooling rates. It is found that the $T_{\mathrm{m} 1}$ decreased, but $T_{\mathrm{m} 2}$ almost constant as the cooling rate increased. This is because at low cooling rate, PLA molecule has more available time to adjust structure and perform diffusion of chains and form more perfect crystal, resulting in higher melting point. The peak at $T_{\mathrm{m} 2}$ might correspond to melt-recrystallization of the unstable crystals formed during the cooling process, and the re-crystallized crystals does not largely change during the heating process. Thus, the high temperature melting point of PLA was less affected. The incorporation of KF hinders the chain segment mobility of the PLA molecules. It decreased the PLA crystallization, which explained the $T_{\mathrm{m} 1}$ and $T_{\mathrm{m} 2}$ of PLA decrease with the incorporation of KF (Xiao et al. 2010).

TABLE 3. Thermal properties of neat PLA and PLA/KF composites determined by DSC after non-isothermal crystallization (second heating at heating rate of $10{ }^{\circ} \mathrm{C} / \mathrm{min}$ )

\begin{tabular}{|c|c|c|c|c|c|c|c|c|}
\hline Sample & $\begin{array}{l}\text { Cooling rate, } \varnothing \\
\left({ }^{\circ} \mathrm{C} / \mathrm{min}\right)\end{array}$ & $\begin{array}{c}T_{\mathrm{g}} \\
\left({ }^{\circ} \mathrm{C}\right)\end{array}$ & $\begin{array}{c}T_{\mathrm{cc}} \\
\left({ }^{\circ} \mathrm{C}\right)\end{array}$ & $\begin{array}{c}H_{\mathrm{cc}} \\
(\mathrm{J} / \mathrm{g})\end{array}$ & $\begin{array}{c}T_{\mathrm{ml}} \\
\left({ }^{\circ} \mathrm{C}\right)\end{array}$ & $\begin{array}{c}T_{\mathrm{m} 2} \\
\left({ }^{\circ} \mathrm{C}\right)\end{array}$ & $\begin{array}{c}H_{\mathrm{m}} \\
(\mathrm{J} / \mathrm{g})\end{array}$ & $\begin{array}{c}X_{\mathrm{c}} \\
(\%)\end{array}$ \\
\hline \multirow[t]{4}{*}{ PLA } & 1 & - & - & - & 154.3 & 158.7 & 49.4 & 55.9 \\
\hline & 2.5 & - & - & - & 151.7 & 158.3 & 47.1 & 53.3 \\
\hline & 5 & - & - & - & 152.0 & 158.3 & 43.5 & 49.2 \\
\hline & 7.5 & 51.5 & 88.1 & 4.4 & 151.1 & 157.6 & 41.0 & 41.5 \\
\hline \multirow[t]{4}{*}{ PLA25 } & 1 & - & - & - & 151.6 & 156.0 & 47.9 & 54.2 \\
\hline & 2.5 & - & - & - & 148.4 & 156.0 & 44.7 & 50.6 \\
\hline & 5 & - & - & - & 150.1 & 156.5 & 39.9 & 45.1 \\
\hline & 7.5 & 50.3 & 94.0 & 11.1 & 148.7 & 155.9 & 40.0 & 32.7 \\
\hline \multirow[t]{4}{*}{ PLA80 } & 1 & - & - & - & 152.9 & 156.7 & 47.6 & 53.8 \\
\hline & 2.5 & - & - & - & 153.1 & 156.5 & 45.2 & 51.2 \\
\hline & 5 & - & - & - & 152.1 & 156.3 & 42.7 & 48.4 \\
\hline & 7.5 & 52.0 & 94.3 & 11.1 & 151.8 & 156.0 & 38.2 & 30.6 \\
\hline \multirow[t]{4}{*}{ PLA106 } & 1 & - & - & - & 153.0 & 158.0 & 48.3 & 54.7 \\
\hline & 2.5 & - & - & - & 150.4 & 157.6 & 44.0 & 49.8 \\
\hline & 5 & - & - & - & 151.7 & 157.7 & 39.4 & 44.6 \\
\hline & 7.5 & 50.0 & 85.3 & 4.3 & 151.1 & 157.3 & 39.2 & 39.6 \\
\hline \multirow[t]{4}{*}{ PLA212 } & 1 & - & - & - & 152.5 & 155.7 & 49.1 & 55.5 \\
\hline & 2.5 & - & - & - & 149.4 & 156.5 & 44.0 & 49.8 \\
\hline & 5 & - & - & - & 150.1 & 156.3 & 39.3 & 44.4 \\
\hline & 7.5 & 50.4 & 92.1 & 8.8 & 150.8 & 157.0 & 34.3 & 28.9 \\
\hline \multirow[t]{4}{*}{ PLA300 } & 1 & - & - & - & 151.7 & 156.7 & 44.8 & 50.7 \\
\hline & 2.5 & - & - & - & 149.1 & 156.3 & 43.4 & 49.2 \\
\hline & 5 & - & - & - & 149.7 & 156.0 & 38.9 & 44.0 \\
\hline & 7.5 & 52.1 & 93.3 & 16.4 & 149.7 & 155.8 & 37.9 & 24.3 \\
\hline
\end{tabular}




\section{NON-ISOTHERMAL CRYSTALLIZATION KINETICS}

The crystallization kinetics of neat PLA and PLA/KF composites were compared in order to further analyze the non-isothermal crystallization process. Based on the experimental data, the relative degree of crystallinity $(X)$ as a function of crystallization temperature $T$ can be calculated from the thermograms measured during the cooling scan according to the formula as follows (Bin et al. 2011):

$$
X_{t}=\frac{\int_{T_{0}}^{T}\left(d H_{c} / d T\right) d T}{\int_{T_{0}}^{T_{\infty}}\left(d H_{c} / d T\right) d T}
$$

where $T_{0}$ and $T_{\infty}$ hold for the onset and end of the crystallization process, respectively; $\mathrm{d} H_{\mathrm{c}}$ is the crystallization enthalpy increment released during an infinitesimal temperature interval; $\mathrm{d} T$ and $T$ is the temperature variable. The crystallization time $(t)$ can be calculated by the following equation (Layachi et al. 2016):

$$
t=\frac{\left(T_{0}-T\right)}{\phi}
$$

where $T$ is temperature at time $t$; and $\phi$ is the cooling rate. $T_{0}$ is the onset temperature at a crystallization time $t=0$.

From DSC non-isothermal crystallization curves of neat PLA and PLA/KF composites, the relative degree of crystallinity $(X)$ as a function of temperature at different cooling rates are shown in Figure 3. It can be observed that all these curves have similar reversed sigmoidal shape with a fast primary crystallization during the early stage and a slow secondary crystallization at the later stage. The curvature of the upper part plot is observed to level off, which already began from the inflection point of the curves because of the spherulites impingement in the final stage of crystallization (Xiao et al. 2010). However, this statement is applicable only to low cooling rates $(\phi$ $\left.\leq 2.5^{\circ} \mathrm{C} / \mathrm{min}\right)$. For the curves for high cooling rates $(\phi$ $\geq 5{ }^{\circ} \mathrm{C} / \mathrm{min}$ ), it can be observed primary crystallization is divided into two-stage where the polymorph of PLA occurs due to the existence of $\alpha$ and $\alpha$ ' phase forms as discussed earlier. The two-stage primary crystallization can be seen when the relative degree of crystallinity is achieved within the range of $20-40 \%$. Upon increased in cooling rate, the reversed sigmoidal isotherms shifted to the left along the temperature axis and the temperature range becomes wider. At a low cooling rates $\left(\phi \leq 2.5{ }^{\circ} \mathrm{C} /\right.$ $\mathrm{min}$ ), the crystallization can occur at a higher temperature range between $130^{\circ} \mathrm{C}$ and $100^{\circ} \mathrm{C}$ where there are sufficient time to activate nuclei. In contrast, when the samples are cooled at high cooling rates $\left(\phi \geq 5{ }^{\circ} \mathrm{C} / \mathrm{min}\right)$ where it covered the temperature range between 100 and $70{ }^{\circ} \mathrm{C}$, the motion of polymer molecular chain unable to follow the cooling rate which require more supercooling to initiate the crystallization (Bin et al. 2011).
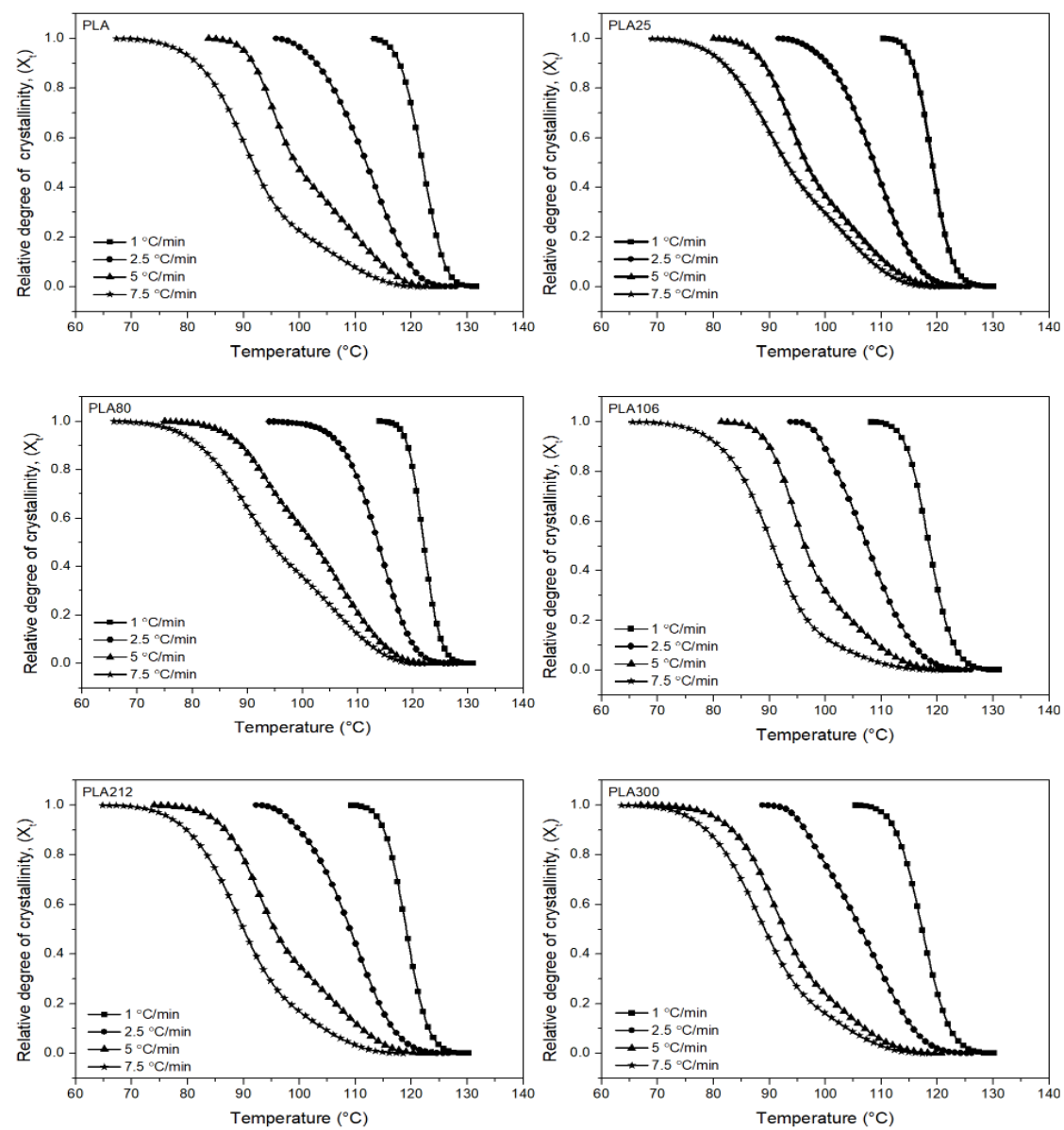

FIGURE 3. Relative degree of crystallinity $\left(X_{t}\right)$ versus temperature for nonisothermal crystallization of PLA and PLA/KF composites at different cooling rates 
Figure 4 shows the relative degree of crystallinity $\left(X_{\mathrm{t}}\right)$ as a function of time of neat PLA and PLA/KF composites at different cooling rates. The plots of $X_{t}$ versus time can be obtained by converting the temperature scale by applying (3) on neat PLA and PLA/KF composites. Apparently, all curves showed an approximately sigmoidal shape, which indicate the fast primary crystallization in the linear segment and slow secondary crystallization in the non-linear segment. Upon decreased in cooling rates, the curves shift to the right indicating the longer time taken for the neat PLA and PLA/KF composites are required to complete the crystallization process. The retardation effect of cooling rate on the crystallization of PLA and its composites is observed only at low cooling rates $(\phi \leq$ $2.5^{\circ} \mathrm{C} / \mathrm{min}$ ), below which the $X_{\mathrm{t}}$ vs time curve shows an apparent sigmoidal shape. At higher cooling rates, melted PLA evolves into the glassy state quickly, thus, the $X_{\mathrm{t}}$ vs time curve tends to be almost the straight line (Xiao et al. $2010)$. From these plots, half-time of crystallization $\left(t_{1 / 2}\right)$ of neat PLA and PLA/KF composites can be analysed. The $t_{1 / 2}$ is defined as the time required to reach $50 \%$ of the final crystallinity and the data of neat PLA and PLA/ $\mathrm{KF}$ composites are listed in Table 2 . The $t_{1 / 2}$ is decreased with increasing in the cooling rate, suggesting that the crystallization rate for all samples increases when cooling rate is increased. In addition, by comparing the $t_{1 / 2}$ values of neat PLA and PLA/KF composites, it is evident that values for most of the PLA/KF composites are higher than neat PLA. It indicates that the incorporation of KF reduces the crystallization rate of the PLA. The incorporation of KF in the PLA apparently become the physical hindrance to the motion of PLA chain and retards the crystallization of PLA. Similar phenomenon had been reported in fibers filled thermoplastic systems (Bin et al. 2011; Pan et al. 2007). However, among the available PLA/KF composites, only PLA80 showed better improvement in terms of crystallization rate at all cooling rate. It is also due to the fact that the $\Delta H_{\mathrm{c}}$ of PLA80 curves are more likely to appear narrower than neat PLA and PLA/KF composites during cooling; probably indicating a drastic reduction in the size of spherulites and increased in nucleation sites. Hence, PLA80 exhibited fastest value of $t_{1 / 2}$ and KF size of $80-106 \mu \mathrm{m}$ is considered to be an optimum size in enhancing crystallization rate of PLA better than other sizes of KF in PLA/KF composites.
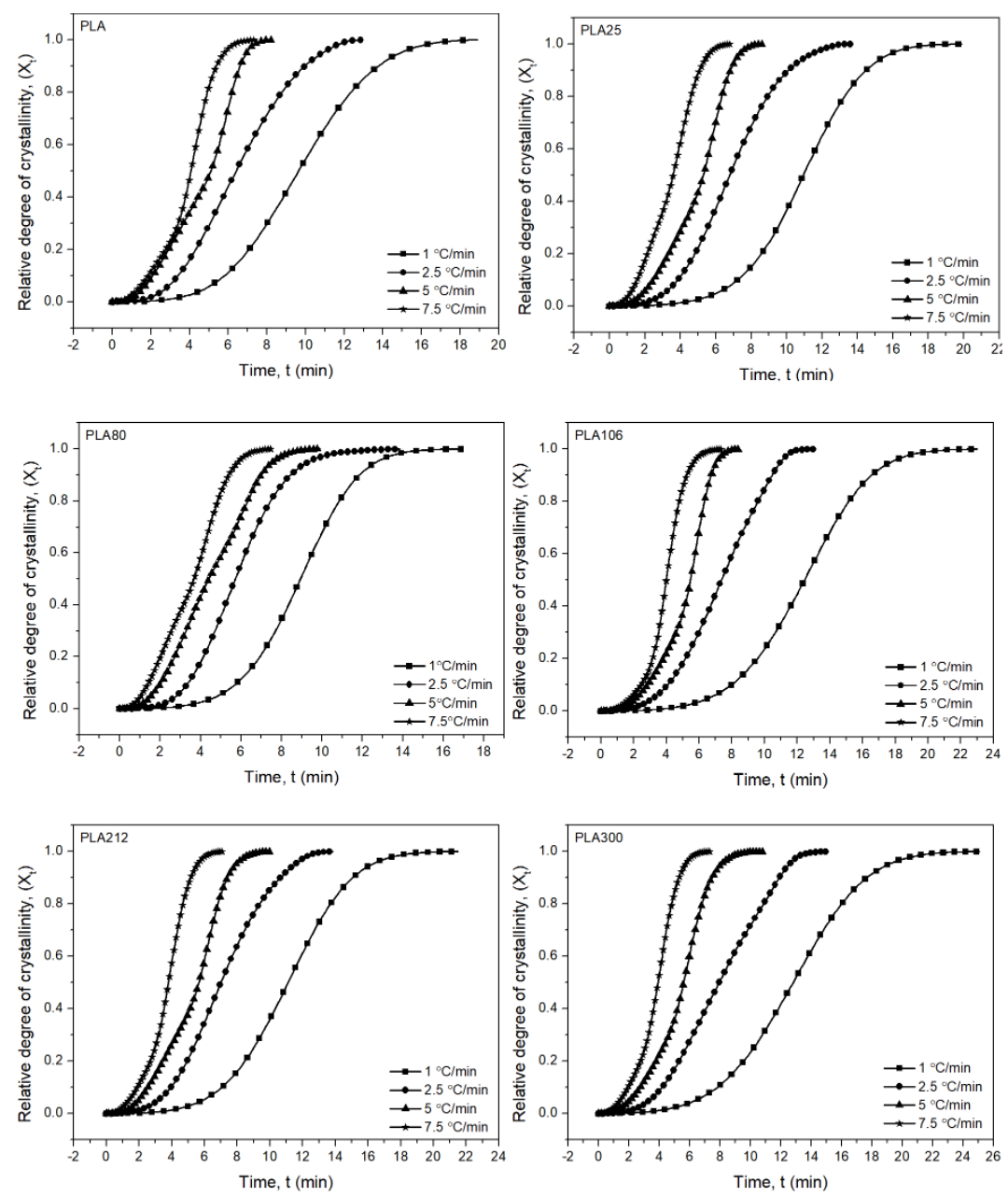

FIGURE 4. Relative degree of crystallinity $\left(X_{t}\right)$ versus time for non-isothermal crystallization of PLA and PLA/KF composites at different cooling rates 


\section{AVRAMI EQUATION}

The Avrami equation can be used to quantify crystallization kinetics and give an indication of the nature of the crystallization process, including nucleation and growth (Meng et al. 2014); it is generally used for analyzing the primary stage of isothermal crystallization behaviour (Layachi et al. 2016). Just like isothermal crystallization analysis, Avrami equation was also adopted as an alternate approach to analyze the non-isothermal crystallization kinetics which is given as following (Bin et al. 2011):

$$
1-X_{t}=\exp \left(-Z_{t} t^{n}\right)
$$

where $X_{\mathrm{t}}$ is the relative degree of crystallinity at the crystallization time $t ; Z_{\mathrm{t}}$ is the crytallization rate constant involving both nucleation and growth rate parameter; and $n$ is the Avrami exponent. The values of $Z_{t}$ and $n$ are calculated from the intercept and slope (Meng et al. 2014), respectively, by the linear for the Avrami equation as follows (Bin et al. 2011):

$$
\log \left[-\ln \left(1-X_{t}\right)\right]=n \log t+\log Z_{t}
$$

The curves of all samples can be divided into two sections which are primary and secondary crystallization process. As the fitting lines of each section are almost parallel, the nucleation mechanism and crystal growth of different cooling rate are comparable for all the samples. When the temperature changes constantly during the non-isothermal crystallization, the parameters $n$ and $Z_{\mathrm{t}}$ do not have the same physical significance as in isothermal crystallization. Considering the influence of cooling rate $\phi\left({ }^{\circ} \mathrm{C} / \mathrm{min}\right)$, Jeziorny suggested a revised rate parameter $Z_{\mathrm{t}}$ giving as following equation (Bin et al. 2011):
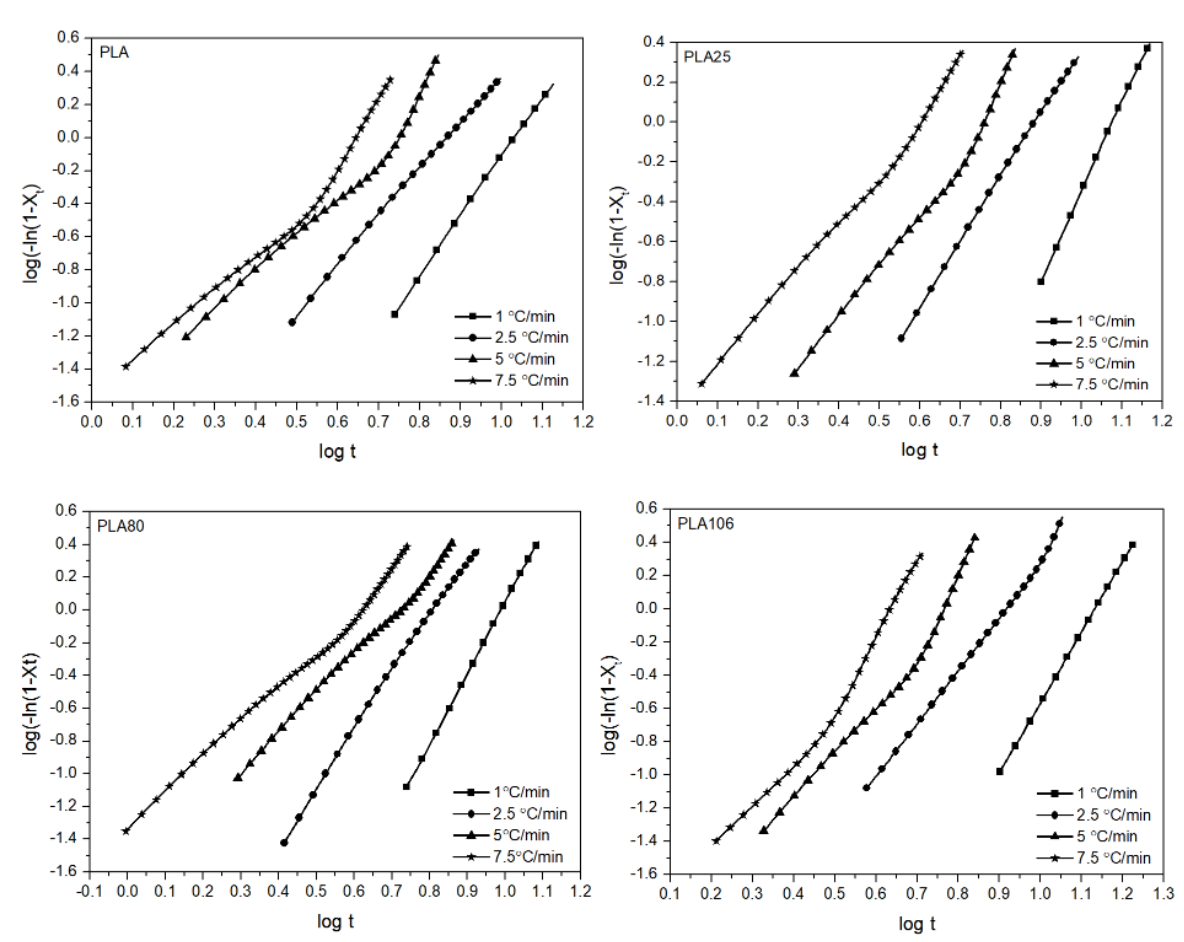
rates. $\min )$ a series of straight lines were obtained and the $n$ values varied from 2.85 to 4.49 . Meanwhile, high cooling rate $\left(\phi \geq 5^{\circ} \mathrm{C} / \mathrm{min}\right)$ showed the non-linearity of the plots where $n_{1}$ varied from 2.03 to 2.43 , and $n_{2}$ range from 3.20 to 5.54 are observed. The value of $n$ is dependent on the crystallization mechanism. The Avrami exponent $n_{1}$ in the range of 3 - 4 implies more complex spherulitic crystal growth with random/heterogeneous nucleation, while $n_{2}$ in the range of 2.2 - 2.9 indicates more simple spherulites with mixture of two-dimensional, three-dimensional and circular disc-like crystal growth. It reflects the presence of different nucleating/crystallization kinetics of the samples due to their different structure (Rinawa et al. 2015). Meanwhile, the value of $Z_{c}$ is increased with the increase of cooling rate, but value of $Z_{\mathrm{c}}$ for neat PLA is larger than PLA/KF composites; suggesting that the crystallization rate increased with increasing of cooling rate and the incorporation of KF in the PLA matrix decreased the crystallization rate. Among the PLA/KF composites, PLA80 showed a fastest crystallization rate at all cooling 

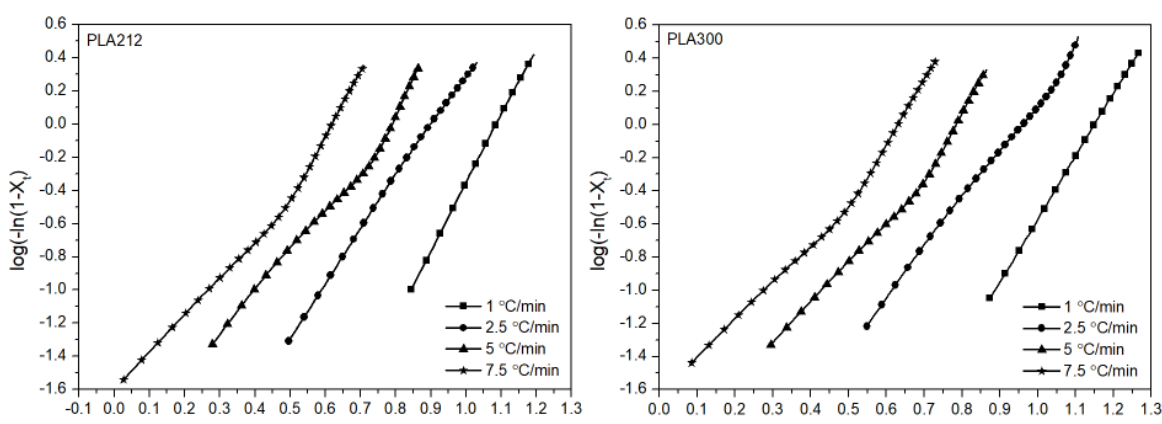

FIGURE 5. Plot of $\log \left(-\ln \left(1-X_{\mathrm{t}}\right)\right)$ versus $\log t$ for non-isothermal crystallization of PLA and PLA/KF composites at different cooling rates

TABLE 4. Kinetic parameters obtained from Avrami analysis of non-isothermal crystallization process for PLA and PLA/ KF composites

\begin{tabular}{|c|c|c|c|c|c|c|c|}
\hline \multirow[b]{2}{*}{ Sample } & \multirow{2}{*}{$\begin{array}{l}\text { Cooling } \\
\text { rate, }(\phi) \\
\left({ }^{\circ} \mathrm{C} / \mathrm{min}\right)\end{array}$} & \multicolumn{3}{|c|}{ Primary crystallization 1} & \multicolumn{3}{|c|}{ Primary crystallization 2} \\
\hline & & $n_{1}$ & $Z_{\mathrm{t} 1}$ & $Z_{\mathrm{c} 1}$ & $n_{2}$ & $Z_{\mathrm{t} 2}$ & $Z_{\mathrm{c} 2}$ \\
\hline \multirow[t]{4}{*}{ PLA } & 1 & 3.59 & -3.70279 & 0.00020 & - & - & - \\
\hline & 2.5 & 2.85 & -2.46761 & 0.10303 & - & - & - \\
\hline & 5 & 2.12 & -1.65163 & 0.46738 & 4.90 & -3.66036 & 0.18532 \\
\hline & 7.5 & 2.00 & -1.52378 & 0.62637 & 4.27 & -2.75469 & 0.42925 \\
\hline \multirow[t]{4}{*}{ PLA25 } & 1 & 4.49 & -4.83495 & 0.00001 & - & - & - \\
\hline & 2.5 & 3.24 & -2.8612 & 0.07170 & - & - & - \\
\hline & 5 & 2.43 & -1.93919 & 0.40941 & 4.64 & -3.51955 & 0.19774 \\
\hline & 7.5 & 2.26 & -1.41602 & 0.64744 & 3.39 & -2.04355 & 0.53398 \\
\hline \multirow[t]{4}{*}{ PLA80 } & 1 & 4.35 & -4.3052 & 0.00005 & - & - & - \\
\hline & 2.5 & 3.47 & -2.80681 & 0.07538 & - & - & - \\
\hline & 5 & 2.31 & -1.65818 & 0.46598 & 3.41 & -2.5258 & 0.31249 \\
\hline & 7.5 & 2.03 & -1.29292 & 0.67237 & 3.20 & -1.98466 & 0.54372 \\
\hline \multirow[t]{4}{*}{ PLA106 } & 1 & 4.35 & -4.82429 & 0.00001 & - & - & - \\
\hline & 2.5 & 3.47 & -3.00029 & 0.06308 & - & - & - \\
\hline & 5 & 2.31 & -2.17337 & 0.36756 & 5.54 & -4.2367 & 0.14212 \\
\hline & 7.5 & 2.03 & -1.93371 & 0.55230 & 4.79 & -3.04623 & 0.39250 \\
\hline \multirow[t]{4}{*}{ PLA212 } & 1 & 4.09 & -4.44303 & 0.00004 & - & - & - \\
\hline & 2.5 & 3.14 & -2.83314 & 0.07358 & - & - & - \\
\hline & 5 & 2.33 & -1.93097 & 0.41097 & 4.43 & -3.49096 & 0.20036 \\
\hline & 7.5 & 2.20 & -1.58998 & 0.61377 & 3.94 & -2.44026 & 0.47275 \\
\hline \multirow[t]{4}{*}{ PLA300 } & 1 & 3.80 & -4.36704 & 0.00004 & - & - & - \\
\hline & 2.5 & 2.91 & -2.77682 & 0.07749 & - & - & - \\
\hline & 5 & 2.35 & -2.00854 & 0.39654 & 4.16 & -3.26404 & 0.22243 \\
\hline & 7.5 & 2.20 & -1.61386 & 0.60928 & 3.94 & -2.48337 & 0.46653 \\
\hline
\end{tabular}


THE OZAWA MODEL

Ozawa developed and modified Avrami equation to take into account the effect of the cooling rate during nonisothermal crystallization. According to the Ozawa theory, thus, the relative degree of crystallinity $\left(X_{t}\right)$ can be written as follows (Layachi et al. 2016):

$$
X_{t}=1-\exp \left(\frac{-K(T)}{\phi^{m}}\right)
$$

and the logarithmic form:

$$
\log \left[-\ln \left(1-X_{t}\right)\right]=\log K(T)-m \log \phi
$$

where $m$ is the Ozawa exponent which depends on the dimension of crystal growth and $K(T)$ is cooling crystallization temperature-dependent function. $K(T)$ is referred to the crystallization rate which indicates how fast crystallization occurs (Meng et al. 2014). The Ozawa plots of $\log (-\ln (1-\mathrm{Xt}))$ versus $\log (\phi)$ for non-isothermal crystallization of PLA and PLA/KF composites at different temperatures are presented in Figure 6. It is obvious that with the changing of cooling rates and with the presence of KF, the Ozawa plots not linear and the changing slopes indicate that $m$ is not constant with the temperature during the crystallization process. Evidently, the Ozawa model unable to provide a satisfactory description of non-isothermal crystallization for neat PLA and PLA/KF composites. The reasons are probably the Ozawa model neglects the slow secondary crystallization and dependence of lamellar thickness on the temperature. The plots also limited only for higher cooling rates. Therefore, it cannot describe the full process of non-isothermal crystallization of polymers in general (Xiao et al. 2010). Likewise, several papers reported that the Ozawa model failed to reflect the actual crystallization process of some polymer systems that influence the Ozawa parameter inconsistent (Bin et al. 2011; Coburn et al. 2018; Xiao et al. 2010).
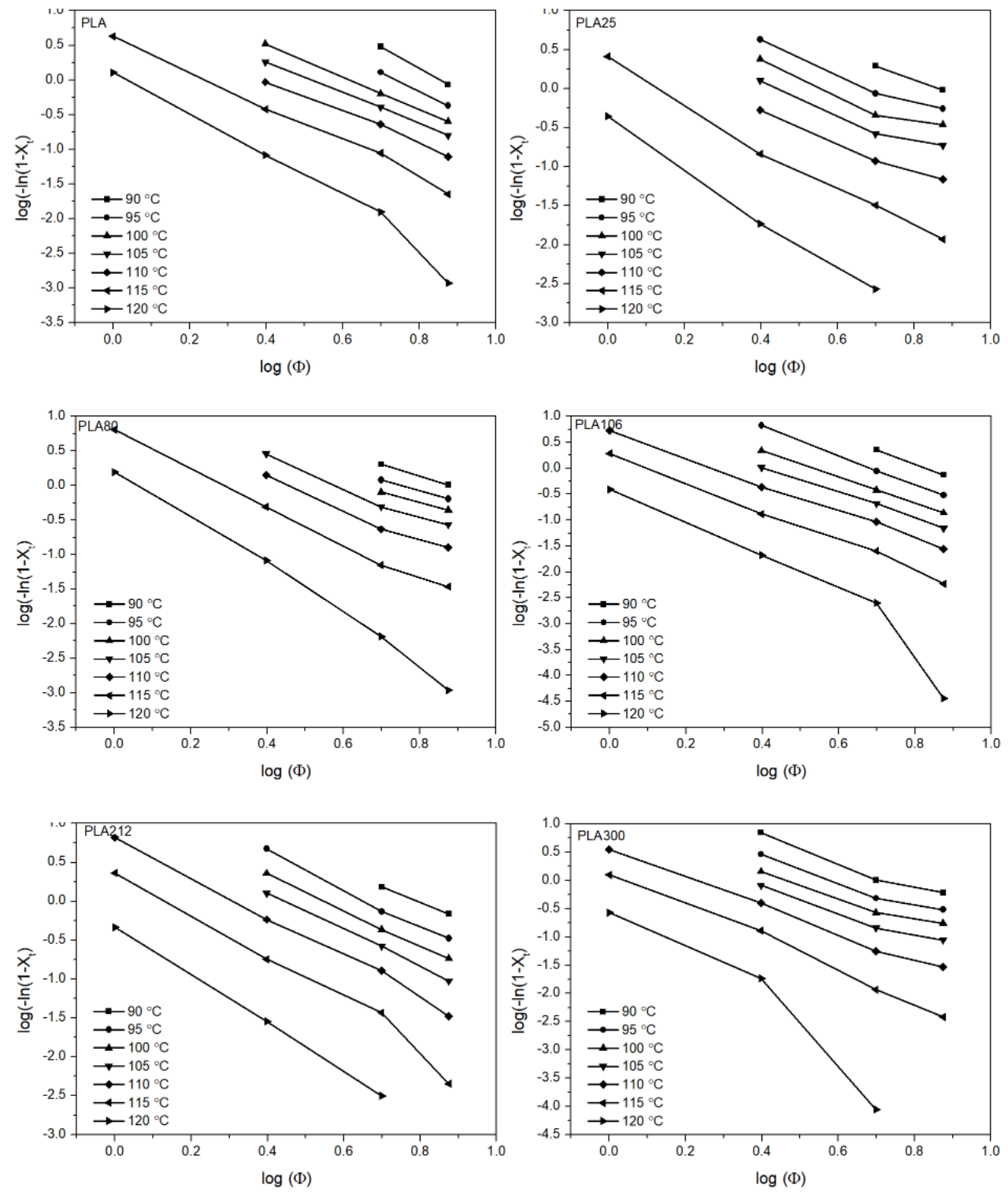

FIGURE 6. Plot of $\log (-\ln (1-\mathrm{Xt}))$ versus $\log (\phi)$ for non-isothermal crystallization of PLA and PLA/KF composites at different temperatures 


\section{THE MO MODEL}

Since the degree of crystallinity is related to the cooling rate $\phi$ and the crystallization time $t$ (or temperature $T$ ), the relationship of $\phi$ and $t$ could be obtained at a given degree of crystallinity (Bin et al. 2011). Hence, a method modified by Mo was also employed to describe the non-isothermal crystallization, which combines the Avrami equation with the Ozawa equation. The final form of modified equation shown as follows (Layachi et al. 2016):

$$
\begin{gathered}
\log Z+n \log t=\log K(T)-m \log \phi \\
\log \phi=\log F(T)-\alpha \log t
\end{gathered}
$$

where $F(T)=[K(T) / Z]^{1 / m}$ and $\alpha=n / m$, the ratio of the Avrami's exponent $n$ to the Ozawa's exponent $m$.

The kinetic parameter $F(T)$ denotes to the value of cooling rate that has to be chosen at unit crystallization time when the measured system amounts to certain degree of crystallinity (Bin et al. 2011). The plot of $\log \varphi$ versus $\log t$ will give a straight line and the value of $F(T)$ and $\alpha$ could be obtained by the intercept and the slope of the line, respectively (Layachi et al. 2016). Figure 7 demonstrates
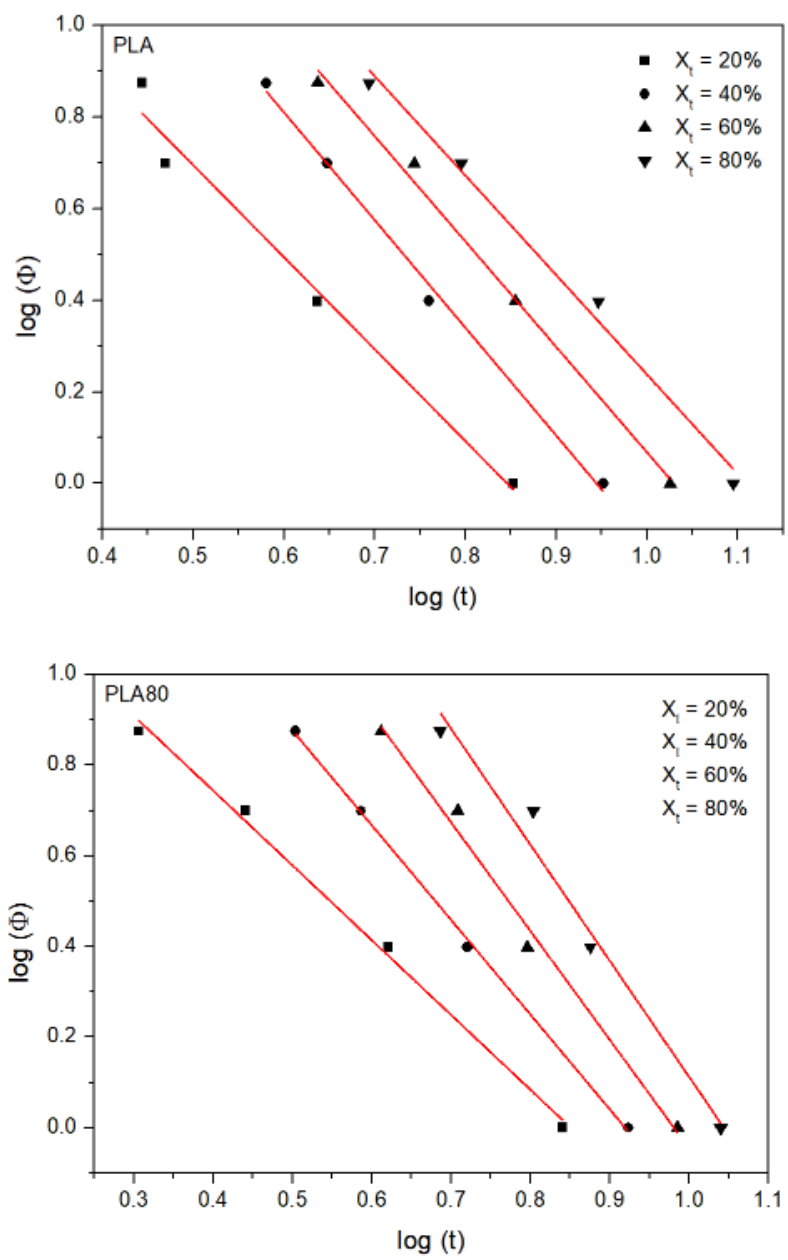

the plot of $\log (\phi)$ versus $\log (t)$ for non-isothermal crystallization of PLA and PLA/KF composites at different values of relative crystallinity. The values of $F(T)$ and $\alpha$ are listed in Table 5. The plots display good linearity, showing that the combined kinetic model is effective for explaining the non-isothermal crystallization of PLA and $\mathrm{PLA} / \mathrm{KF}$ composites. It can be observed the values of $\alpha$ for neat PLA are higher than most of the PLA/KF composites except PLA80 at high cooling rates $\left(\phi \geq\right.$ of $\left.5{ }^{\circ} \mathrm{C} / \mathrm{min}\right)$. The values of $F(T)$ for all samples increase with the increase of relative degree of crystallinity, signifying that in order to achieve a higher degree of crystallinity, higher cooling rate should be used. $F(T)$ considered as a parameter that indicates the polymer crystallization rate. A lower $F(T)$ value means a higher crystallization under non-isothermal crystallization rate (Xiao et al. 2010). PLA25 and PLA80 had smaller $F(T)$ values than the neat PLA at low cooling rate $\left(\phi \leq 2.5^{\circ} \mathrm{C} / \mathrm{min}\right)$ which indicates that the added smaller KF accelerate PLA crystallization rate. The results are almost consistent with $Z_{\mathrm{c}}$ and $t_{1 / 2}$ especially for PLA80 composites. For all samples, linear efficiency coefficient is achieved high at $R^{2} \geq 0.97$ which prove that log $\phi$ versus $\log t$ well obeys Mo's theoretical linear correlation.
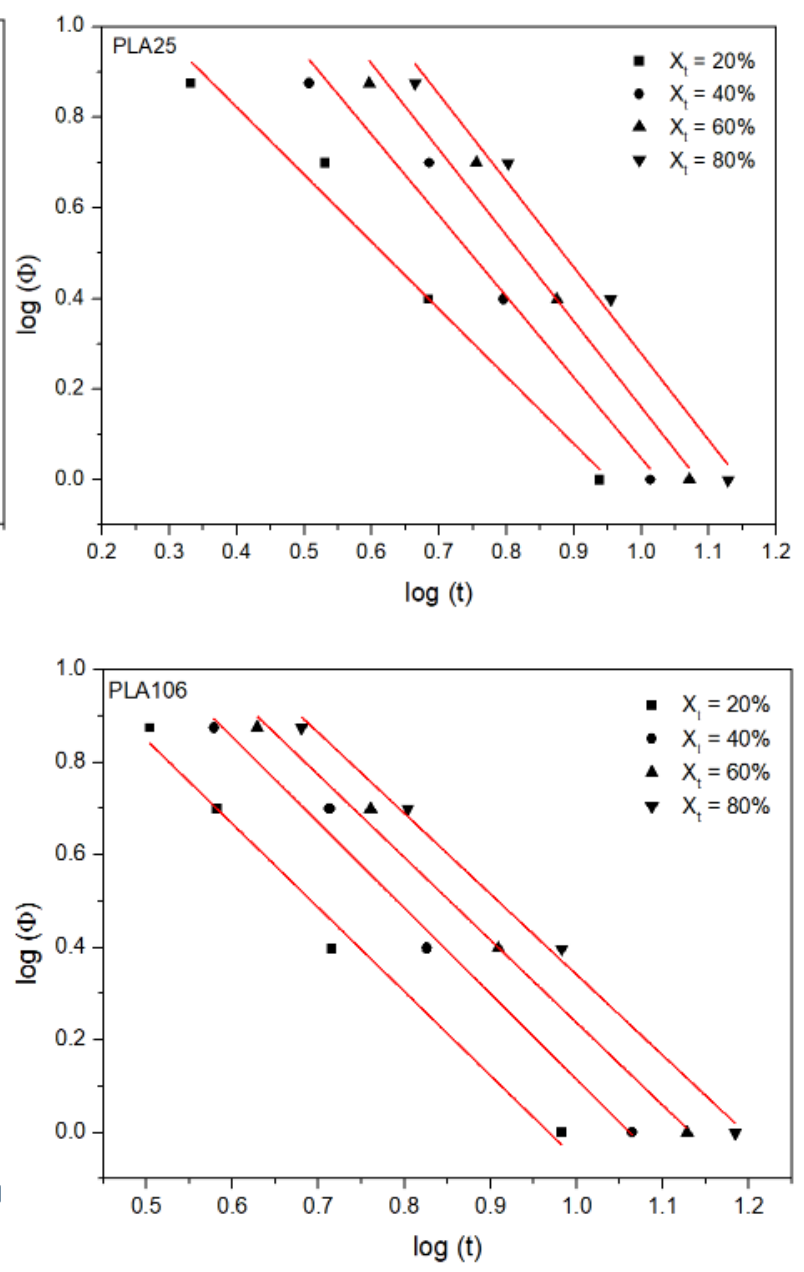

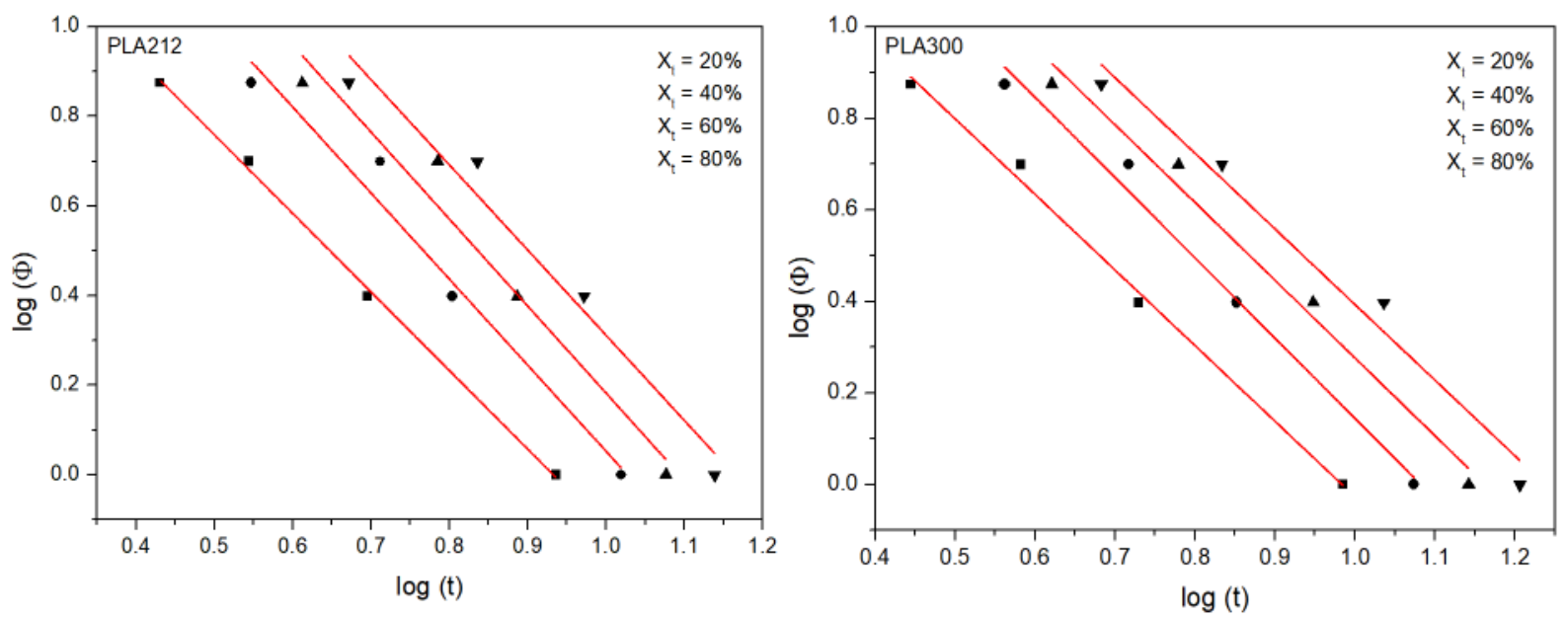

FIGURE 7. Plot of $\log (\varnothing)$ versus $\log (t)$ for non-isothermal crystallization of

PLA and PLA/KF composites at different values of relative crystallinity

TABLE 5. Non-isothermal crystallization kinetic parameters based on the Mo model

\begin{tabular}{|c|c|c|c|c|}
\hline Sample & $X_{t}(\%)$ & $F(T)$ & $\alpha$ & $R^{2}$ \\
\hline \multirow[t]{4}{*}{ PLA } & 20 & 50.18 & 2.01 & 0.9713 \\
\hline & 40 & 167.16 & 2.35 & 0.9931 \\
\hline & 60 & 234.62 & 2.30 & 0.9914 \\
\hline & 80 & 257.44 & 2.17 & 0.9866 \\
\hline \multirow[t]{4}{*}{ PLA25 } & 20 & 26.04 & 1.49 & 0.9730 \\
\hline & 40 & 68.01 & 1.79 & 0.9607 \\
\hline & 60 & 113.49 & 1.89 & 0.9702 \\
\hline & 80 & 152.79 & 1.91 & 0.9797 \\
\hline \multirow[t]{4}{*}{ PLA80 } & 20 & 25.32 & 1.65 & 0.9944 \\
\hline & 40 & 83.41 & 2.09 & 0.9985 \\
\hline & 60 & 224.88 & 2.40 & 0.9853 \\
\hline & 80 & 470.02 & 2.56 & 0.9669 \\
\hline \multirow[t]{4}{*}{ PLA106 } & 20 & 56.98 & 1.81 & 0.9818 \\
\hline & 40 & 92.10 & 1.85 & 0.9835 \\
\hline & 60 & 105.18 & 1.78 & 0.9937 \\
\hline & 80 & 121.22 & 1.74 & 0.9935 \\
\hline \multirow[t]{4}{*}{ PLA212 } & 20 & 43.11 & 1.75 & 0.9976 \\
\hline & 40 & 93.75 & 1.92 & 0.9593 \\
\hline & 60 & 132.77 & 1.94 & 0.9501 \\
\hline & 80 & 162.90 & 1.90 & 0.9569 \\
\hline \multirow[t]{4}{*}{ PLA300 } & 20 & 42.22 & 1.65 & 0.9933 \\
\hline & 40 & 79.37 & 1.76 & 0.9827 \\
\hline & 60 & 94.58 & 1.70 & 0.9778 \\
\hline & 80 & 111.17 & 1.65 & 0.9672 \\
\hline
\end{tabular}


THE KISSINGER ACTIVATION ENERGY OF NONISOTHERMAL CRYSTALLIZATION

The activation energy $\Delta E$ during the non-isothermal crystallization process is deduced by deriving an expression of the combination of the cooling rate $\phi$ and crystallization peak $T_{\mathrm{p}}$. Kissinger suggested an equation to calculate the activation energy $\Delta E$ for non-isothermal crystallization as follows (Layachi et al. 2016):

$$
\frac{d\left[\ln \left(\phi / T_{p}^{2}\right)\right]}{d\left(1 / T_{p}\right)}=-\Delta E / R
$$

where $\phi$ is the cooling rate; $\mathrm{R}$ is the universal gas constant (8.314 $\mathrm{J} \mathrm{mol}^{-1} \mathrm{k}^{-1}$ ) (Meng et al. 2014), and $\Delta E$ is the activation energy at different cooling. It is easy by integrating the Kissinger equation, the final expression can be formulated as follows (Layachi et al. 2016):

$$
\ln \left(\phi / T_{p}^{2}\right)=\left(1 / T_{p}\right)(-\Delta E / R)
$$

where $\ln \left(\phi / T_{\mathrm{p}}{ }^{2}\right)$ versus $1 / T_{\mathrm{p}}$ can be obtained as a linear relationship, the slope of which shows the value of $-\Delta E / R$.

The activation energy $(\Delta E)$ of neat PLA and PLA/ $\mathrm{KF}$ composites can be derived from the plot of $\ln (\phi /$ $T_{\mathrm{p}}{ }^{2}$ ) versus $1 / T_{\mathrm{p}}$ in Figure 8 . It can be seen that the $\Delta E$ for PLA/KF composites is dependent on the sizes of the KF in PLA matrix. The linear efficiency coefficient of the activation energy plots are recorded high at $R^{2} \geq 0.91$. The $\Delta E$ of neat PLA is $173 \mathrm{~kJ} / \mathrm{mol}$, which is approximately consistent with the values obtained by other researchers which are 106, 201.7, and $103 \mathrm{~kJ} / \mathrm{mol}$ (Jin et al. 2017; Kim et al. 2008; Myoung et al. 2016). The values of $\Delta E$ for most of PLA/KF composites are recorded higher than neat PLA with 191, 203, 180, and $182 \mathrm{~kJ} / \mathrm{mol}$ for PLA25, PLA106, PLA212, and PLA300, respectively. However, PLA80 recorded the lowest value of $\Delta E$ at $161 \mathrm{~kJ} / \mathrm{mol}$ as compared to neat PLA and PLA/KF composites. The results indicate that the KF size between 80 - $106 \mu \mathrm{m}$ accelerates the non-crystallization of PLA which is in accordance with the results of crystallization kinetics study.

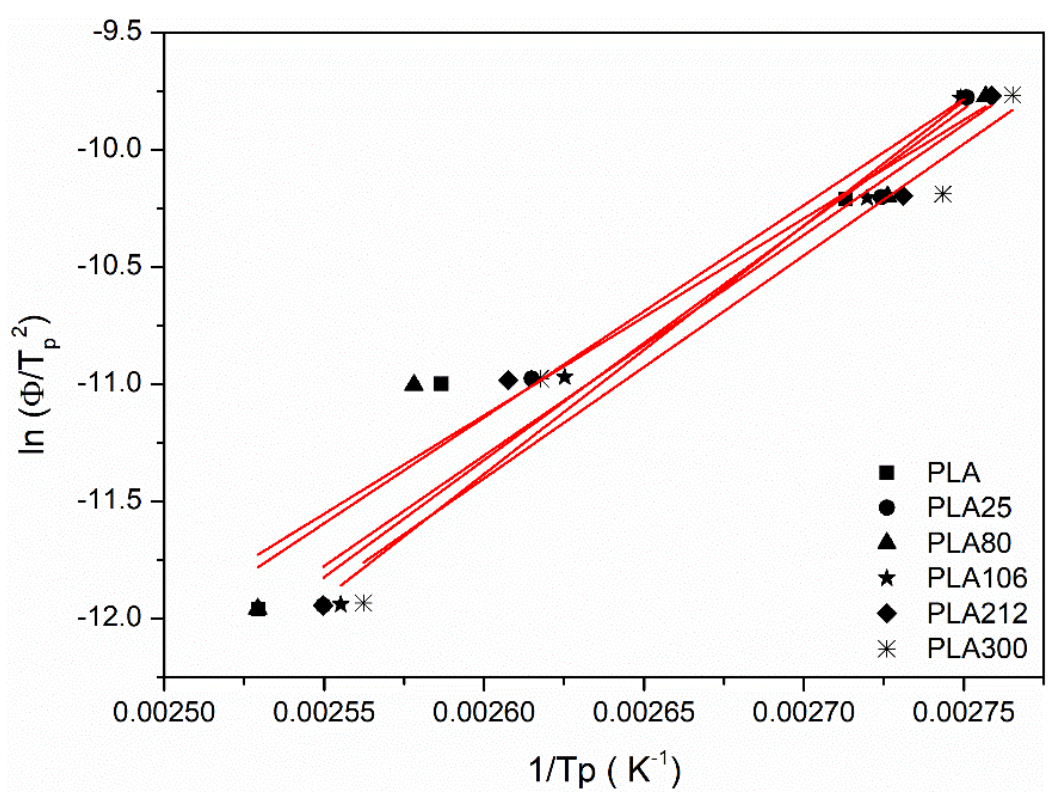

FIGURE 8. Non-isothermal crystallization activation energy of neat PLA and PLA/KF composites

\section{CONCLUSION}

The non-isothermal crystallization kinetics of neat PLA and PLA/KF composites was studied with DSC at cooling rate ranging from 1 to $7.5^{\circ} \mathrm{C} / \mathrm{min}$. The $\mathrm{KF}$ size of 80-106 $\mu \mathrm{m}$ accelerates the crystallization rate of the PLA during non-isothermal crystallization since the half-time of crystallization $\left(t_{1 / 2}\right)$ were lower than neat PLA, but higher than other KF sizes at low cooling rate $\left(\phi \leq 2.5^{\circ} \mathrm{C} / \mathrm{min}\right)$. The results were in accordance with the crystallization rate constant $\left(Z_{\mathrm{c}}\right)$ in Avrami equation and rate constant 
$F(T)$ in Mo methods; and successfully explained the nonisothermal crystallization kinetics of the neat PLA and PLA/KF composites. Meanwhile, Ozawa method was failed to describe the crystallization kinetics of the systems. The crystallization activation energies were calculated from the slopes. It was found that the $\Delta E$ value of the PLA80 composite was the lowest as compared to neat PLA and $\mathrm{PLA} / \mathrm{KF}$ composites. The lower activation energy was in agreement with the faster overall crystallization rate.

\section{ACKNOWLEDGEMENTS}

This project has been supported by RUI Grant from Universiti Sains Malaysia (1001/PBAHAN/8014042).

\section{REFERENCES}

Akhtar, M.N., Sulong, A.B., Radzi, M.F., Ismail, N.F., Raza, M.R., Muhamad, N. \& Khan, M.A. 2016. Influence of alkaline treatment and fiber loading on the physical and mechanical properties of kenaf/polypropylene composites for variety of applications. Progress in Natural Science: Materials International 26(6): 657-664.

Avérous, L. 2008. Polylactic acid: Synthesis, properties and applications. In Monomers, Polymers and Composites from Renewable Resources. New York: Elsevier. pp. 433-450.

Bai, Z.F. \& Dou, Q. 2016. Non-isothermal crystallization kinetics of polypropylene/poly (lactic acid)/maleic anhydridegrafted polypropylene blends. Journal of Thermal Analysis and Calorimetry 126(2): 785-794.

Bin, T., Qu, J.P., Liu, L.M., Feng, Y.H., Hu, S.X. \& Yin, X.C. 2011. Non-isothermal crystallization kinetics and dynamic mechanical thermal properties of poly (butylene succinate) composites reinforced with cotton stalk bast fibers. Thermochimica Acta 525(1-2): 141-149.

Bouzouita, A., Samuel, C., Notta-Cuvier, D., Odent, J., Lauro, F., Dubois, P. \& Raquez, J.M. 2016. Design of highly tough poly (1-lactide)-based ternary blends for automotive applications. Journal of Applied Polymer Science 133(19): 43402.

Chen, P.Y., Lian, H.Y., Shih, Y.F., Chen-Wei, S.M. \& Jeng, R.J. 2017. Preparation, characterization and crystallization kinetics of kenaf fiber/multi-walled carbon nanotube/ polylactic acid (PLA) green composites. Materials Chemistry and Physics 196: 249-255.

Chung, T.J., Park, J.W., Lee, H.J., Kwon, H.J., Kim, H.J., Lee, Y.K. \& Tai, Y.T.W. 2018. The improvement of mechanical properties, thermal stability, and water absorption resistance of an eco-friendly PLA/kenaf biocomposite using acetylation. Applied Sciences 8(3): 376.

Coburn, N., Douglas, P., Kaya, D., Gupta, J. \& McNally, T. 2018. Isothermal and non-isothermal crystallization kinetics of composites of poly (propylene) and MWCNTs. Advanced Industrial and Engineering Polymer Research 1(1): 99-110.

Elsawy, M.A., Kim, K.H., Park, J.W. \& Deep, A. 2017. Hydrolytic degradation of polylactic acid (PLA) and its composites. Renewable and Sustainable Energy Reviews 79: 1346-1352.

El-Shekeil, Y.A., Salit, M.S., Abdan, K. \& Zainudin, E.S. 2011. Development of a new kenaf bast fiber-reinforced thermoplastic polyurethane composite. BioResources 6(4): 4662-4672.
Gorrasi, G. \& Pantani, R. 2013. Effect of PLA grades and morphologies on hydrolytic degradation at composting temperature: Assessment of structural modification and kinetic parameters. Polymer Degradation and Stability 98(5): 1006-1014.

Ho, M.P., Lau, K.T., Wang, H. \& Hui, D. 2015. Improvement on the properties of polylactic acid (PLA) using bamboo charcoal particles. Composites Part B: Engineering 81: 14-25.

Jain, S., Misra, M., Mohanty, A.K. \& Ghosh, A.K. 2012. Thermal, mechanical and rheological behavior of poly (lactic acid)/talc composites. Journal of Polymers and the Environment 20(4): 1027-1037.

Jalali, A., Huneault, M.A. \& Elkoun, S. 2017. Effect of molecular weight on the nucleation efficiency of poly (lactic acid) crystalline phases. Journal of Polymer Research 24(11): 182.

Jin, X., Chen, X., Cheng, Q., Zhang, N., Cai, S. \& Ren, J. 2017. Non-isothermal crystallization kinetics of ramie fiberreinforced polylactic acid biocomposite. RSC Advances 7(73): 46014-46021.

Jonoobi, M., Harun, J., Mathew, A.P. \& Oksman, K. 2010. Mechanical properties of cellulose nanofiber (CNF) reinforced polylactic acid (PLA) prepared by twin screw extrusion. Composites Science and Technology 70(12): 1742-1747.

Kim, H.S., Park, B.H., Choi, J.H. \& Yoon, J.S. 2008. Mechanical properties and thermal stability of poly (L-lactide)/calcium carbonate composites. Journal of Applied Polymer Science 109(5): 3087-3092.

Kowalczyk, M., Piorkowska, E., Kulpinski, P. \& Pracella, M. 2011. Mechanical and thermal properties of PLA composites with cellulose nanofibers and standard size fibers. Composites Part A: Applied Science and Manufacturing 42(10): 1509-1514.

Layachi, A., Frihi, D., Satha, H., Seguela, R. \& Gherib, S. 2016. Non-isothermal crystallization kinetics of polyamide $66 /$ glass fibers/carbon black composites. Journal of Thermal Analysis and Calorimetry 124(3): 1319-1329.

Lee, S.H. \& Wang, S. 2006. Biodegradable polymers/bamboo fiber biocomposite with bio-based coupling agent. Composites Part A: Applied Science and Manufacturing 37(1): 80-91.

Li, J., Li, J., Feng, D., Zhao, J., Sun, J. \& Li, D. 2017. Excellent rheological performance and impact toughness of cellulose nanofibers/PLA/ionomer composite. RSC Advances 7(46): 28889-28897.

Lin, W.Y., Shih, Y.F., Lin, C.H., Lee, C.C. \& Yu, Y.H. 2013. The preparation of multi-walled carbon nanotube/poly (lactic acid) composites with excellent conductivity. Journal of the Taiwan Institute of Chemical Engineers 44(3): 489-496.

Masirek, R., Kulinski, Z., Chionna, D., Piorkowska, E. \& Pracella, M. 2007. Composites of poly (L-lactide) with hemp fibers: Morphology and thermal and mechanical properties. Journal of Applied Polymer Science 105(1): 255-268.

Meng, Z., Yang, L., Geng, W., Yao, Y., Wang, X. \& Liu, Y. 2014. Kinetic study on the isothermal and nonisothermal crystallization of monoglyceride organogels. The Scientific World Journal 2014: Article ID. 149753.

Myoung, S.H., Im, S.S. \& Kim, S.H. 2016. Non-isothermal crystallization behavior of PLA/acetylated cellulose nanocrystal/silica nanocomposites. Polymer International 65(1): 115-124. 
Notta-Cuvier, D., Odent, J., Delille, R., Murariu, M., Lauro, F., Raquez, J.M., Bennani, B. \& Dubois, P. 2014. Tailoring polylactide (PLA) properties for automotive applications: Effect of addition of designed additives on main mechanical properties. Polymer Testing 36: 1-9.

Pan, P., Zhu, B., Kai, W., Dong, T. \& Inoue, Y. 2008. Effect of crystallization temperature on crystal modifications and crystallization kinetics of poly (L-lactide). Journal of Applied Polymer Science 107(1): 54-62.

Pan, P., Zhu, B., Kai, W., Serizawa, S., Iji, M. \& Inoue, Y, 2007. Crystallization behavior and mechanical properties of bio-based green composites based on poly (L-lactide) and kenaf fiber. Journal of Applied Polymer Science 105(3): 1511-1520.

Petinakis, E., Yu, L., Edward, G., Dean, K., Liu, H. \& Scully, A.D. 2009. Effect of matrix-particle interfacial adhesion on the mechanical properties of poly (lactic acid)/wood-flour micro-composites. Journal of Polymers and the Environment 17(2): 83-94.

Ren, Z., Dong, L. \& Yang, Y. 2006. Dynamic mechanical and thermal properties of plasticized poly (lactic acid). Journal of Applied Polymer Science 101(3): 1583-1590.

Rinawa, K., Maiti, S.N., Sonnier, R. \& Cuesta, J.L. 2015. Nonisothermal crystallization kinetics and thermal behaviour of PA12/SEBS-g-MA blends. Bulletin of Materials Science 38(5): 1315-1327.

Saeidlou, S., Huneault, M.A., Li, H., Sammut, P. \& Park, C.B. 2012. Evidence of a dual network/spherulitic crystalline morphology in PLA stereocomplexes. Polymer 53(25): 5816-5824.

Silverajah, V.S., Ibrahim, N.A., Yunus, W.M.Z.W., Hassan, H.A. \& Woei, C.B. 2012. A comparative study on the mechanical, thermal and morphological characterization of poly (lactic acid)/epoxidized palm oil blend. International Journal of Molecular Sciences 13(5): 5878-5898.

Suryanegara, L., Nakagaito, A.N. \& Yano, H. 2009. The effect of crystallization of PLA on the thermal and mechanical properties of microfibrillated cellulose-reinforced PLA composites. Composites Science and Technology 69(7-8): 1187-1192.

Volpe, V., De Filitto, M., Klofacova, V., De Santis, F. \& Pantani, R. 2018. Effect of mold opening on the properties of PLA samples obtained by foam injection molding. Polymer Engineering \& Science 58(4): 475-484.

Xiao, H., Yang, L., Ren, X., Jiang, T. \& Yeh, J.T. 2010. Kinetics and crystal structure of poly (lactic acid) crystallized nonisothermally: Effect of plasticizer and nucleating agent. Polymer Composites 31(12): 2057-2068.

Yu, T., Hu, C., Chen, X. \& Li, Y. 2015. Effect of diisocyanates as compatibilizer on the properties of ramie/poly (lactic acid) (PLA) composites. Composites Part A: Applied Science and Manufacturing 76: 20-27.

Yusoff, R.B., Takagi, H. \& Nakagaito, A.N. 2016. Tensile and flexural properties of polylactic acid-based hybrid green composites reinforced by kenaf, bamboo and coir fibers. Industrial Crops and Products 94: 562-573.

Zaldua, N., Mugica, A., Zubitur, M., Iturrospe, A., Arbe, A., Re, G.L., Raquez, J.M., Dubois, P. \& Müller, A.J. 2016. The role of PLLA-g-montmorillonite nanohybrids in the acceleration of the crystallization rate of a commercial PLA. CrystEngComm 18(48): 9334-9344.

Zamri, M.H., Md Akil, H., Mohd Ishak, Z.A. \& Abu Bakar, A. 2015. Effect of different fiber loadings and sizes on pultruded kenaf fiber reinforced unsaturated polyester composites. Polymer Composites 36(7): 1224-1229.

School of Materials and Mineral Resources Engineering Engineering Campus

Universiti Sains Malaysia

14300 Nibong Tebal, Pulau Pinang

Malaysia

*Corresponding author; email: razaina@usm.my

Received: 15 October 2019

Accepted: 8 May 2020 